Even if the results of this study suggest prolonged waiting time does not worsen postoperative outcomes in patients with stenosis of the left main coronary artery, it remains essential to keep the waiting time short to reduce the risk while waiting and thus the total risk for patients accepted for CABG.

Dr. Rexius is from the Department of Cardiothoracic Surgery, Sahlgrenska University Hospital, Gothenburg, Sweden.

Competing interests: None declared.

\section{References}

1. Naylor CD, Baigrie RS, Goldman BS, Basinski A. Assessment of priority for coronary revascularisation procedures. Revascularisation Panel and Consensus Methods Group. Lancet 1990;335:1070-3.

2. Morgan CD, Sykora K, Naylor CD. Analysis of deaths while waiting for cardiac surgery among 29,293 consecutive patients in Ontario, Canada. The Steering Committee of the Cardiac Care Network of Ontario. Heart 1998;79: 345-9.

3. Rexius H, Brandrup-Wognsen G, Oden A, Jeppsson A. Mortality on the waiting list for coronary artery bypass grafting: incidence and risk factors. Ann Thorac Surg 2004;77:769-74.

4. Légaré JF, MacLean A, Buth KJ, Sullivan JA. Assessing the risk of waiting for coronary artery bypass graft surgery among patients with stenosis of the left main coronary artery. CMA7 2005;173(4):371-5

5. Koomen EM, Hutten BA, Kelder JC, Redekop WK, Tijssen JG, Kingma JH. Morbidity and mortality in patients waiting for coronary artery bypass surgery. Eur 7 Cardiothorac Surg 2001;19:260-5.

6. Plomp J, Redekop WK, Dekker FW, van Geldorp TR, Haalebos MM, Jambroes G, et al. Death on the waiting list for cardiac surgery in The Netherlands in 1994 and 1995. Heart 1999;81:593-7.

7. Suttorp MJ, Kingma JH, Vos J, Koomen EM, Tijssen JG, Vermeulen FE, et al. Determinants for early mortality in patients awaiting coronary artery bypass graft surgery: a case-control study. Eur Heart 7 1992;13:238-42.

8. Corbineau H, Lebreton H, Langanay T, Logeais Y, Leguerrier A. Prospective evaluation of coronary arteries: influence on operative risk in coronary artery surgery. Eur 7 Cardiothorac Surg 1999;16:429-34.

9. Gol MK, Ozsoyler I, Sener E, Goksel S, Saritas A, Tasdemir O, et al. Is left main coronary artery stenosis a risk factor for early mortality in coronary artery surgery? 7 Card Surg 2000;15:217-22

10. Ray AA, Buth KJ, Sullivan JA, Johnstone DE, Hirsch GM. Waiting for cardiac surgery: results of a risk-stratified queuing process. Circulation 2001;104 (Suppl 1):I92-8.

11. Rexius H, Brandrup-Wognsen G, Oden A, Jeppsson A. Waiting time and mortality after elective coronary artery bypass grafting. Ann Thorac Surg 2005 79:538-43.

Correspondence to: Dr. Helena Rexius, Department of Cardiothoracic Surgery, Sahlgrenska University Hospital, SE 41345 Gothenburg, Sweden; fax +46 314179 91; helena.rexius@hjl.gu.se

\title{
A new childhood pathway for transmission of an increased likelihood of smoking?
}

\section{Nicholas Anthonisen, Robert Murray}

§ See related article page 377

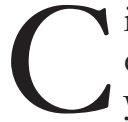
igarette use has long been known to be a prominent cause of illness and death, although only this year has a randomized controlled trial demonstrating this been published. ${ }^{1}$ Nonetheless, the many cohort studies coming to this same conclusion led to many interventions to alleviate the harm from cigarettes. The earliest of these were concerned primarily with adult smoking cessation. They often produced significant outcomes in terms of disease prevention, but were limited by success rates (i.e., quit rates) below $30 \%$ and by the number of smokers ready to enter the programs at any given time. Meanwhile, interventions at the policy level included control of the price of cigarettes, restrictions on smoking in public spaces, public education about the dangers of smoking cigarettes and others. In combination, these interventions have had considerable effect on the rate of smoking among adults.

About a decade ago, because locational tobacco smoke was identified as a major contributor to various childhood diseases such as lower respiratory infections and asthma, attention turned to interventions to minimize children's exposure to secondhand smoke. Most environmental exposure is a result of parents' smoking in the home and family car. Parental smoking is not only a major source of secondhand smoke but also a primary pathway to smoking initiation by adolescents: Evidence suggests that until the age of about 12 years (after which peers predominate), the predominant role models for children are their parents. ${ }^{2}$

Twin studies have shown that about $75 \%$ of the variance in smoking initiation is heritable, ${ }^{3}$ whereas a crosscultural review attributed $46 \%$ in women and $57 \%$ in men. ${ }^{4}$ Parental smoking is clearly a key determinant of children's smoking, although the mechanisms of transmission are not yet entirely described. Moreover, there is little evidence that smoking-prevention interventions aimed at adolescents are efficacious. ${ }^{5}$ Clearly, the transmission of a 
tendency to initiate smoking from parents to children is an important concern.

The study by Becklake, Ghezzo and Ernst ${ }^{6}$ in this issue suggests a new mechanism by which early childhood exposure to tobacco smoke may enhance the likelihood of adolescent smoking. The proposed pathway is physiological, a link between evidence of nicotine exposure in early childhood to an increased risk of nicotine dependence in adolescence. If this pathway is confirmed by subsequent studies, it offers a parsimonious explanation of how cigarette smoking may be passed from one generation to the next.

In their novel and stimulating study, Becklake and colleagues examined schoolchildren twice, more than 2 years apart. They assessed home sociocultural factors and measured lung function. They also measured salivary cotinine at the first visit, to assess nicotine exposure due to environmental tobacco smoke. Between surveys, $44 \%$ of the children became smokers (a discouraging statistic). The authors then related characteristics of the first survey to subsequent smoking behaviour. In postpubertal children, $56 \%$ of whom had become smokers, the usual environmental factors were noted: more smokers in the home tended to increase the risk of smoking, whereas a decrease in the number of adult smokers at home tended to decrease the adolescent's risk. These associations can presumably be ascribed to role-modeling. However, the unique finding was that salivary cotinine at the first survey predicted smoking behaviour at the second: the higher the concentration of cotinine, the more likely it was that smoking would be initiated subsequently.

As already noted, cotinine levels in nonsmoking children reflect exposure to secondhand smoke, which in turn relates to the number of smokers in the home, their habitual intake and crowding. One would expect these environmental factors to increase the likelihood of future smoking, and future smoking was indeed predicted by cotinine levels per se. However, this result was maintained after statistical adjustment for number of smokers at home, number of cigarettes smoked at home and home crowding; that is, for factors related to environmental exposure. Because the statistical adjustment of the cotinine levels was successful, then levels reflected the response to a given level of secondhand tobacco smoke; in other words, to nicotine uptake given a particular level of exposure. Becklake and colleagues suggest that a large vital capacity of the lungs, which is a (weak) risk factor for smoking, may facilitate nicotine uptake. This implies a much more subtle mechanism, a susceptibility to the influence of secondhand smoke, which is not yet understood. On the other hand, starting smoking, like most human behaviours, cannot be explained by environmental factors alone. Host factors must also play a role, and one of them might be nicotine uptake given a particular exposure.

Host factors are important in all smoking-related diseases, simply because many smokers apparently "get away" with smoking - that is, they somehow avoid developing any of the diseases associated with smoking. Substantial efforts are underway to identify genetic characteristics that render people susceptible to the malignant effects of tobacco smoke, with some degree of success. If the findings of Becklake's group are reproduced, they will define a new phenotype to be studied. However, should genetic determinants of smoking-related diseases or behaviours be identified, we may have to confront the issue of whether anti-smoking interventions should be directed at susceptible subpopulations, possibly at the expense of efforts aimed at the population at large.

From the Respiratory Hospital, Health Sciences Centre (Anthonisen) and the Alcohol and Tobacco Research Unit, Department of Community Health Sciences, University of Manitoba (Murray), Winnipeg, Man.

Competing interests: None declared.

Contributors: The coauthors contributed equally to the writing and review of this commentary, and both approved the final version for publication.

Acknowledgement: It is a pleasure to be able to comment on the work of Canada's leading respiratory epidemiologist. Over many years, Dr. Becklake has made numerous important scientific contributions to the field, as well as serving as tutor and inspiration to many investigators, including N.A.

\section{References}

1. Anthonisen NR, Skeans MA, Wise RA, Manfreda J, Kanner RE, Connett JE. The effects of a smoking cessation intervention on 14.5-year mortality: a randomized clinical trial. Ann Intern Med 2005;142:233-9.

2. Vitaro F, Wanner B, Brendgen M, Gosselin C, Gendreau PL. Differential contribution of parents and friends to smoking trajectories during adolescence. Addict Behav 2004;29:831-5.

3. Maes HH, Sullivan PF, Bulik CM, Neale MC, Prescott CA, Eaves LJ, et al. A twin study of genetic and environmental influences on tobacco initiation, regular tobacco use and nicotine dependence. Psychol Med 2004:34:1251-61.

4. Madden PAF, Pedersen NL, Kaprio J, Koskenvuo MJ, Martin NG. The epidemiology and genetics of smoking initiation and persistence: cross-cultural comparisons of twin study results. Twin Research 2004;7:82-97.

5. Christakis DA, Garrison MM, Ebel BE, Wiebe SE, Rivara FP. Pediatric smoking prevention interventions delivered by care providers: a systematic review. Am 7 Prev Med 2003;25:358-62.

6. Becklake MR, Ghezzo H, Ernst P. Childhood predictors of smoking in adolescence: a follow-up study of Montréal schoolchildren. CMAJ 2005;173(4): $377-9$.

Correspondence to: Dr. Nicholas Anthonisen, Respiratory

Hospital, 810 Sherbrook Street, Winnipeg MB R3A 1R8; fax 204

787-1220; NAnthonisen@exchange.hsc.mb.ca 